\title{
Efeito da adição do mio-inositol para determinados parâmetros de avaliação do sêmen caprino pós-criopreservação
}

\author{
[Effect of myo-inositol addition in goat spermatozoa after cryopreservation]
}

\section{"Artigo Científico/Scientific Article"}

\author{
Rafael Souza Limongi, Camilla Flávia Avelino Farias, Alex Souza Rique, \\ Jorge Silva-Neto, Sildivane Valcácia Silva*
}

\begin{abstract}
Laboratório de Biotecnologia em Reprodução Animal (LABRA), Centro de Biotecnologia (CBiotec), Campus I, Universidade Federal da Paraíba (UFPB), João Pessoa-PB, Brasil.

*Autor para correspondência/Corresponding author: E-mail: sildivane@ cbiotec.ufpb.br
\end{abstract}

\begin{abstract}
Resumo
Objetivou-se avaliar o efeito da adição de mio-inositol ao sêmen caprino pós-descongelação. Amostras seminais de diferentes reprodutores caprinos da raça Boer $(n=3)$ foram descongeladas $\left(37^{\circ} \mathrm{C} / 30 \mathrm{~s}\right)$ e homogeneizadas para formação do pool. Quatro grupos experimentais foram formados: $\mathrm{GC}=$ grupo controle, sem adição de antioxidante; G1=sêmen $+5 \mathrm{mM}$ de mio-inositol; G2=sêmen $+15 \mathrm{mM}$ de mio-inositol; G3=sêmen $+30 \mathrm{mM}$ de mio-inositol, sendo submetidos às avaliações de motilidade subjetiva, integridade e funcionalidade da membrana plasmática nos períodos $0 \mathrm{~h}, 2 \mathrm{~h}$ a $25^{\circ} \mathrm{C}$ e $2 \mathrm{~h}$ a $37^{\circ} \mathrm{C}$ pós-descongelação. Não houve diferença $(\mathrm{P}>0,05)$ entre o grupo controle e os suplementados com mio-inositol para o parâmetro de motilidade total nos momentos pós-descongelação e $2 \mathrm{~h}$ de incubação a $25^{\circ} \mathrm{C}$. No momento $2 \mathrm{~h}$ a $37^{\circ} \mathrm{C}$ houve redução de $30 \%(\mathrm{P}<0,05)$ dos parâmetros cinéticos quando comparados ao momento pós-descongelação e $10 \%$ após $2 \mathrm{~h}$ a $25^{\circ} \mathrm{C}$. Não foram observadas diferenças $(\mathrm{P}>0,05)$ para os parâmetros de integridade e funcionalidade da membrana plasmática entre os grupos tratados e o grupo controle. A adição de mio-inositol, na concentração de $30 \mathrm{mM}$, reduz a motilidade de espermatozoides caprinos após duas horas de incubação a $37^{\circ} \mathrm{C}$.
\end{abstract}

Palavras-chave: antioxidante; descongelação; espermatozoide; motilidade.

\begin{abstract}
The effect of myo-inositol addition in post-thaw goat semen was evaluated in this study. Seminal samples from different Boer goat breeders $(n=3)$ were thawed $\left(37^{\circ} \mathrm{C} / 30 \mathrm{~s}\right)$ and homogenized to form a pool. Four experimental groups were formed: $\mathrm{CG}=$ control group, without antioxidant; $\mathrm{G} 1=$ semen $+5 \mathrm{mM}$ myo-inositol; $\mathrm{G} 2=$ semen $+15 \mathrm{mM}$ myo-inositol; G3=semen $+30 \mathrm{mM}$ myo-inositol. Subjective sperm motility and plasma membrane functionality and integrity after incubation for $2 \mathrm{~h}$ at $25^{\circ} \mathrm{C}$ and $2 \mathrm{~h}$ at $37^{\circ} \mathrm{C}$ post-thawing were evaluated. No significant differences $(\mathrm{P}>0.05)$ were observed in post-thaw sperm motility between the control group and the ones supplemented with myo-inositol after $2 \mathrm{~h}$ of incubation at $25^{\circ} \mathrm{C}$. There was a $30 \%$ reduction $(\mathrm{P}<0.05)$ of the kinematic parameters after $2 \mathrm{~h}$ at $37^{\circ} \mathrm{C}$, and $10 \%$ when compared to $2 \mathrm{~h}$ at $25^{\circ} \mathrm{C}$. No significant differences $(\mathrm{P}>0.05)$ were observed for the integrity and functionality of plasma membrane parameters between treated and control groups. Myo-inositol at $30 \mathrm{mM}$ reduced goat sperm motility after two hours of incubation at $37^{\circ} \mathrm{C}$.
\end{abstract}

Keywords: antioxidant; thawing; spermatozoon; motility.

\section{Introdução}

A criopreservação de sêmen consiste em submeter espermatozoides a temperaturas abaixo da condição corporal $\left( \pm 38^{\circ} \mathrm{C}\right)$ para reduzir ou inativar o seu metabolismo, por refrigeração ou congelação, respectivamente. Assim, este material Recebido 14 de dezembro de 2017. Aceito 18 de outubro de 2018 DOI: https://doi.org/10.26605/medvet-v12n2-2122 
armazenado por tempo indeterminado (Mariante et al., 2011).

Espermatozoides de caprinos pósdescongelados, entretanto, ainda apresentam resultados aquém dos alcançados na bovinocultura quando utilizados em programas de inseminação artificial. Diferentemente da criopreservação do sêmen de bovinos, que tem aplicabilidade real e excelentes resultados, fruto de pesquisas realizadas há décadas, a preservação de gametas caprinos permanece em condições experimentais.

No plasma seminal do ejaculado caprino há presença de fosfolipases, enzimas que interagem tanto com a membrana plasmática do espermatozoide quanto com os componentes do diluente, promovendo a formação de substâncias tóxicas que danificam o espermatozoide caprino (La Falci et al., 2002). Desta forma, a centrifugação para remoção do plasma seminal é uma etapa do processamento do sêmen para criopreservação. Por outro lado, esta centrifugação pode promover estresse mecânico às células, como ainda aumenta o tempo de manipulação das células espermáticas (Oliveira et al., 2017). Esta exposição favorece a formação de espécies reativas ao oxigênio (ERO) que interferem na integridade da membrana plasmática (Borges et al., 2011). A membrana plasmática cede fosfolipídios para estabilizar as ERO, alterando sua conformação e reconhecimento estrutural, evento conhecido como peroxidação lipídica, tornando-se inviável para executar as cascatas de capacitação espermática e reação acrossomal com consequente perda da capacidade fertilizante do espermatozoide (Patricio et al., 2016).

O Inositol, encontrado mais abundantemente na forma de mio-inositol (cis-1,2,3,4-trans-4,6cicloexanoexol) é um poli-álcool cíclico que desempenha importante papel como base estrutural para mensageiros secundários em células eucarióticas. Proveniente do metabolismo da glicose, o mio-inositol é encontrado em tecidos animais como um componente dos fosfolipídios e encontra-se no cérebro e fluido cérebro-espinhal, sendo encontrado ainda no esqueleto, músculo cardíaco e outros tecidos (Croze e Soulage, 2013). O nível de inositol livre é especialmente elevado em todos os órgãos do trato reprodutor masculino, particularmente no fluido seminal (Pruneda et al., 2007).

Na técnica de criopreservação do sêmen caprino, entretanto, antes do sêmen ser submetido às curvas de refrigeração e congelação, se faz necessário o processo de centrifugação do sêmen para remoção do plasma seminal, como citado anteriormente. Assim, os antioxidantes presentes no plasma, como o mio-inositol, são igualmente removidos, diminuindo drasticamente suas concentrações, o que pode comprometer o sistema de defesa antioxidante.

Em estudo com humanos foi observado que o mio-inositol melhora a atividade mitocondrial dos espermatozoides com consequente aumento da capacidade móvel da célula espermática (Condorelli et al., 2012). Na criopreservação do sêmen ovino foram adicionadas diferentes concentrações de mio-inositol ao diluente de congelação e após análise, percebeu-se que a concentração de $10 \mathrm{mM}$ foi eficiente na redução dos níveis de malonaldeído, subproduto da peroxidação lipídica, um dos marcadores do estresse oxidativo (Kulaksiz et al., 2011). Em contrapartida, o mio-inositol no sêmen de equinos foi acrescentado na concentração de $30 \mathrm{mM}$ durante o processo de refrigeração sem produzir efeitos sobre a viabilidade espermática (Affonso et al., 2017).

Diante da diversidade de estudos com a adição do mio-inositol em diferentes espécies animais, assim como em variadas concentrações, objetivou-se avaliar o efeito da adição de mioinositol no sêmen caprino após a criopreservação.

\section{Material e Métodos}

\section{Obtenção de Amostras e Local}

Neste trabalho foram utilizadas amostras congeladas de sêmen caprino da raça Boer, obtidas em central de reprodução, no ano de 2007, armazenadas em botijão criogênico $\left(-196^{\circ} \mathrm{C}\right) . \mathrm{O}$ sêmen caprino, colhido por método de vagina artificial, foi submetido a centrifugação para remoção do plasma seminal, por duas vezes, diluído individualmente em leite desnatado $(10 \mathrm{~g}$ de leite em pó desnatado, $194 \mathrm{mg}$ de glicose, $100 \mathrm{~mL}$ de água bidestilada, aquecimento a $90^{\circ} \mathrm{C}$ por 10 minutos, $3 \mathrm{mg}$ de Penicilina e Estreptomicina, 7\% de glicerol) e submetido à criopreservação em sistema automatizado (TK 3000 ${ }^{\circledR}$ ) - informações cedidas pela Central. O experimento foi realizado no Laboratório de Biotecnologia em Reprodução Animal (LABRA), lotado no Centro de Biotecnologia (CBiotec) da Universidade Federal da Paraíba, Campus I, João Pessoa. 


\section{Delineamento Experimental}

Foram descongeladas seis palhetas $(0,25$ $\mathrm{mL})$ de diferentes reprodutores $(\mathrm{n}=3)$ à temperatura de $37^{\circ} \mathrm{C}$ por 30 segundos. Após descongelação, as amostras foram homogeneizadas para formação do pool com o objetivo de reduzir a interferência individual, conforme descrito por Bucak et al. (2008). Na sequência foram formados quatro grupos experimentais, sendo o Grupo Controle (GC) sem adição do antioxidante, o Grupo 1 (G1) com adição de $5 \mathrm{mM}$ de mio-inositol, o Grupo 2 (G2) com adição de $15 \mathrm{mM}$ de mio-inositol e o Grupo 3 (G3) com adição de $30 \mathrm{mM}$ de mioinositol. De cada grupo foram utilizados $10 \mu \mathrm{L}$ para avaliação subjetiva da motilidade e do teste hiposmótico (HOST) e $20 \mu \mathrm{L}$ foram utilizados para avaliação com o corante Eosina-Nigrosina (EN), nos momentos 0 e 2 horas (h) pós-descongelação. Após a primeira avaliação, realizada imediatamente após a descongelação, os grupos foram divididos em dois grupos de incubação, sendo um à temperatura ambiente $\left(25^{\circ} \mathrm{C}\right)$ e outro à temperatura de incubação a $37^{\circ} \mathrm{C}$ (Figura 1). Foram realizadas quatro repetições e cada repetição foi realizada em triplicata.

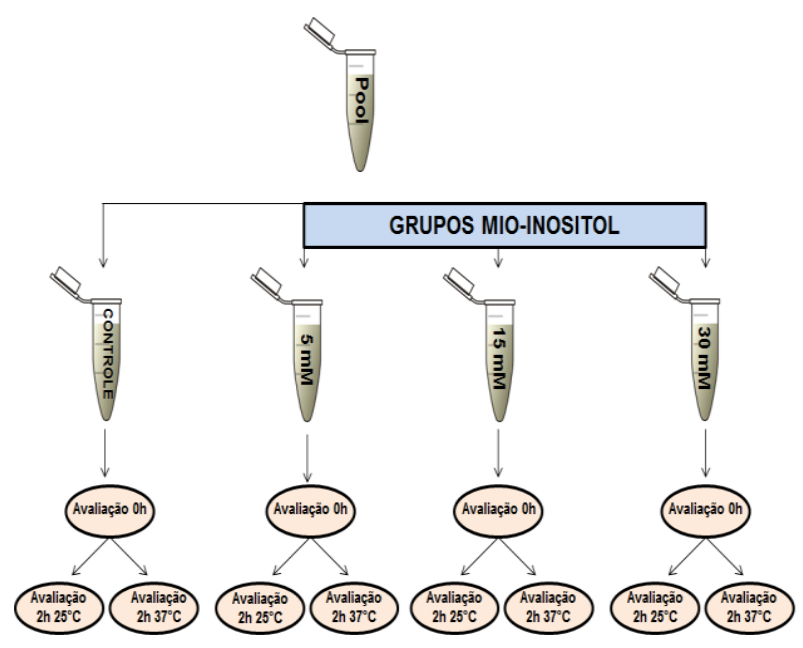

Figura 1. Delineamento experimental para avaliação da adição do antioxidante mio-inositol ao sêmen caprino pós-descongelação.

\section{Análise Espermática \\ Motilidade Espermática}

A motilidade espermática foi avaliada subjetivamente com a deposição de $10 \mu \mathrm{L}$ de sêmen entre lâmina e lamínula (18x18) em microscópio ótico (Coleman, São Paulo) com aumento de 40x. A avaliação da motilidade foi expressa em porcentagem considerando a média de dois avaliadores, conforme recomendado pelo CBRA (2013).
Teste de Funcionalidade da Membrana Plasmática

O teste hiposmótico (HOST) foi empregado para avaliar a funcionalidade da membrana plasmática dos espermatozoides caprinos. A leitura do percentual de reação dos espermatozoides ao HOST foi feita através de microscopia ótica com aumento de 40 vezes, colocando-se $10 \mu \mathrm{L}$ de sêmen/solução entre lâmina e lamínula. Foram retirados $10 \mu \mathrm{L}$ de cada grupo experimental, onde este foi diluído em $100 \mu \mathrm{L}$ de solução hiposmótica (100 mOsm $/ \mathrm{Kg} \mathrm{H}_{2} \mathrm{O}$ ), composta por citrato de sódio, frutose e água destilada, como preconizado por Oliveira e colaboradores (2013). Após a incubação, a $37^{\circ} \mathrm{C}$ por 30 minutos foi acrescentado $50 \mu \mathrm{L}$ de solução formol-salina com o objetivo de estabilizar a reação osmótica dos espermatozoides. As células foram classificadas quanto à presença ou não de cauda enrolada. Com o objetivo de minimizar o erro de leitura e interpretação do percentual de reação ao HOST, foi utilizada a fórmula proposta por Melo e Henry (1999), na qual, contando-se 100 células, subtrai-se as células com cauda enrolada encontradas na avaliação da morfologia espermática.

\section{Teste de Integridade da Membrana Plasmática}

Para este teste foi empregada dupla coloração com os corantes eosina-nigrosina, conforme proposto pelo CBRA (2013). Para realização desta técnica foram diluídos $20 \mu \mathrm{L}$ de sêmen de cada grupo experimental em solução contendo $20 \mu \mathrm{L}$ do corante e $20 \mu \mathrm{L}$ de solução fisiológica. Após a diluição, foi realizado o estiraço com $10 \mu \mathrm{L}$ de cada amostra e realizada a contagem de 200 células com aumento de 40x.

\section{Análise Estatística}

Para comparação entre os grupos GC, G1, G2 e G3 e cada parâmetro avaliado utilizou-se o método de análise de variância (ANOVA) e teste de Tukey, caso identificado variação entre os grupos e os tempos de incubação, com nível de significância de 5\%.

\section{Resultados}

Os dados da motilidade total foram expressos na forma de média e desvio padrão (Tabela 1). Como observado nesta tabela, não houve diferença significativa $(P>0,05)$ entre os grupos controle e os suplementados com mioinositol, considerando os momentos pósdescongelação e $2 \mathrm{~h}$ de incubação a $25^{\circ} \mathrm{C}$. Porém, foi observado que os grupos avaliados no momento 
$2 \mathrm{~h}$ a $37^{\circ} \mathrm{C}$ demonstraram redução $(\mathrm{P}<0,05)$ dos parâmetros cinéticos quando comparados ao momento pós-descongelação e $2 \mathrm{~h}$ após a descongelação, a $25^{\circ} \mathrm{C}$.

Tabela 1. Porcentual (média \pm desvio padrão) de motilidade subjetiva de espermatozoides caprino da raça Boer, pós-descongelação, com adição ou não de mio-inositol.

\begin{tabular}{cccc} 
& \multicolumn{3}{c}{ Motilidade Total $(\%)$} \\
\cline { 2 - 4 } Grupos & T0 & T2 $\left(\mathbf{2 5} \mathbf{C}^{\circ}\right)$ & T2 $\left(\mathbf{3 7}^{\circ} \mathbf{C}\right)$ \\
\hline GC & $65,00 \pm 7,36^{\mathrm{Aa}}$ & $55,62 \pm 14,77^{\mathrm{A}}$ & $38,75 \pm 13,62^{\mathrm{Ba}}$ \\
G1 & $55,00 \pm 4,56^{\mathrm{Aa}}$ & $57,13 \pm 6,37^{\mathrm{Aa}}$ & $33,75 \pm 11,82^{\mathrm{Bab}}$ \\
G2 & $62,50 \pm 10,99^{\mathrm{Aa}}$ & $50,63 \pm 7,18^{\mathrm{Aa}}$ & $31,25 \pm 4,33^{\mathrm{Bab}}$ \\
G3 & $58,75 \pm 11,99^{\mathrm{Aa}}$ & $53,13 \pm 6,58^{\mathrm{Aa}}$ & $19,38 \pm 5,54^{\mathrm{Bb}}$ \\
\hline
\end{tabular}

GC= Grupo Controle; G1 = Grupo 1 (5 mM de Mio-inositol); G2= Grupo 2 (15 mM de Mio-inositol); G3= Grupo 3 (30 mM de Mio-inositol). T0= Momento de avaliação pós-descongelação; T2 $\left(25^{\circ} \mathrm{C}\right)=$ Momento de avaliação $2 \mathrm{~h}$ pós-descongelação à temperatura ambiente; T2 $\left(37^{\circ} \mathrm{C}\right)=$ Momento de avaliação $2 \mathrm{~h}$ pós-descongelação e incubação a $37^{\circ} \mathrm{C}$. Letras maiúsculas diferentes na mesma linha indicam diferença entre os tempos de avaliação. Letras minúsculas na mesma coluna indicam diferença entre os grupos.

Os parâmetros obtidos nas avaliações de integridade e funcionalidade da membrana plasmática estão descritos nas Tabelas 2 e 3, na forma de média e desvio padrão. Não houve diferença significativa $(\mathrm{p}>0,05)$ para estes parâmetros tanto para o grupo controle quanto para os grupos que receberam concentrações de mioinositol nos tempos de incubação.

Tabela 2. Porcentual (média \pm desvio padrão) de integridade da membrana plasmática de espermatozoides caprino da raça Boer, pós-descongelação, com adição ou não de mio-inositol.

\begin{tabular}{cccc}
\hline & \multicolumn{3}{c}{ Integridade de Membrana Plasmática (\%) } \\
\cline { 2 - 4 } Grupos & T0 & T2 $\left(\mathbf{2 5}^{\circ} \mathbf{C}\right)$ & $\mathbf{T 2 ~}^{\left(37^{\circ} \mathbf{C}\right)}$ \\
\hline GC & $48,69 \pm 4,71^{\mathrm{a}}$ & $46,81 \pm 4,42^{\mathrm{a}}$ & $40,38 \pm 1,89^{\mathrm{a}}$ \\
G1 & $48,44 \pm 2,07^{\mathrm{a}}$ & $44,56 \pm 5,07^{\mathrm{a}}$ & $46,94 \pm 7,61^{\mathrm{a}}$ \\
G2 & $48,81 \pm 5,44^{\mathrm{a}}$ & $47,13 \pm 7,09^{\mathrm{a}}$ & $43,69 \pm 3,99^{\mathrm{a}}$ \\
G3 & $52,88 \pm 5,96^{\mathrm{a}}$ & $50,68 \pm 9,04^{\mathrm{a}}$ & $45,31 \pm 6,99^{\mathrm{a}}$ \\
\hline
\end{tabular}

GC= Grupo Controle; G1 = Grupo 1 (5 mM de Mio-inositol); G2= Grupo 2 (15 mM de Mio-inositol); G3= Grupo 3 (30 mM de Mio-inositol). T0= Momento de avaliação pós-descongelação; $\mathrm{T} 2\left(25^{\circ} \mathrm{C}\right)=$ Momento de avaliação $2 \mathrm{~h}$ pós-descongelação à temperatura ambiente; $\mathrm{T} 2\left(37^{\circ} \mathrm{C}\right)=$ Momento de avaliação $2 \mathrm{~h}$ pós-descongelação e incubação a $37^{\circ} \mathrm{C}$. Letras iguais na mesma coluna e/ou linha indicam não haver diferença estatística $(\mathrm{P}>0,05)$.

Tabela 3. Porcentual (média \pm desvio padrão) de funcionalidade da membrana plasmática de espermatozoides caprino da raça Boer, pós-descongelação, com adição ou não de mio-inositol.

\begin{tabular}{cccc}
\hline & \multicolumn{3}{c}{ Funcionalidade de Membrana Plasmática (\%) } \\
\cline { 2 - 4 } Grupos & T0 & ${\text { T2 }\left(25^{\circ} \mathbf{C}\right)}^{\mathrm{T}}\left(\mathbf{3 7}^{\circ} \mathbf{C}\right)$ \\
\hline GC & $41,13 \pm 7,76^{\mathrm{a}}$ & $40,25 \pm 3,20^{\mathrm{a}}$ & $44,75 \pm 6,14^{\mathrm{a}}$ \\
G1 & $40,88 \pm 6,52^{\mathrm{a}}$ & $43,63 \pm 7,73^{\mathrm{a}}$ & $43,38=11,56^{\mathrm{a}}$ \\
G2 & $42,25 \pm 6,17^{\mathrm{a}}$ & $44,13 \pm 5,15^{\mathrm{a}}$ & $38,50 \pm 9,17^{\mathrm{a}}$ \\
G3 & $43,38 \pm 7,23^{\mathrm{a}}$ & $47,88 \pm 8,20^{\mathrm{a}}$ & $36,00 \pm 7,74^{\mathrm{a}}$ \\
\hline
\end{tabular}

GC= Grupo Controle; G1= Grupo 1 (5 mM de Mio-inositol); G2= Grupo 2 (15 mM de Mio-inositol); G3= Grupo 3 (30 mM de Mio-inositol). T0= Momento de avaliação pós-descongelação; T2 $\left(25^{\circ} \mathrm{C}\right)=$ Momento de avaliação $2 \mathrm{~h}$ pós-descongelação à temperatura ambiente; T2 $\left(37^{\circ} \mathrm{C}\right)=$ Momento de avaliação $2 \mathrm{~h}$ pós-descongelação e incubação a $37^{\circ} \mathrm{C}$. Letras iguais na mesma coluna e/ou linha indicam não haver diferença estatística $(\mathrm{P}>0,05)$.

\section{Discussão}

A redução da motilidade observada nos grupos mantidos na temperatura de $37^{\circ} \mathrm{C}$, após $2 \mathrm{~h}$ de descongelação, pode ser atribuída à manutenção da temperatura que é similar a do trato genital da fêmea. A temperatura pode ter mantido a atividade flagelar do espermatozoide, com consequente aumento do consumo energético, e estimulado a célula espermática a sofrer o processo de capacitação. Esse processo envolve mudanças bioquímicas e estruturais das membranas celulares (Assumpção et al., 2002). Tais mudanças alteram as concentrações iônicas intracelulares, a fluidez da membrana plasmática, o metabolismo e a motilidade dos espermatozoides (Yanagamachi, 
1994), características necessárias para a reação do acrossoma com a zona pelúcida do oócito.

Flesch e Gadelha (2000) observaram que espermatozoides de humano e suíno possuem maior tempo de latência para sofrer o processo de capacitação, de quatro a cinco horas, o que não é observado em ovinos, que ocorre em aproximadamente em 2h. Além disso, o sêmen caprino criopreservado é desprovido de substâncias secretadas pelas glândulas sexuais acessórias, as quais inibem a habilidade do espermatozoide de fecundar o óvulo (decapacitação), prevenindo a ocorrência de capacitação prematura (Sidhu e Guraya, 1989). Estes fatores, associados à temperatura, podem ter possibilitado o processo de capacitação da célula nestas $2 \mathrm{~h}$ de incubação, entretanto, como não houve fecundação, o espermatozoide sofreu degradação, produzindo substâncias tóxicas, como ERO, que se acumulam no meio e causam a morte das outras células, diminuindo a quantidade de espermatozoides móveis.

Observou-se que entre os grupos incubados a $37^{\circ} \mathrm{C}$ por $2 \mathrm{~h}$ pós-descongelação, o $\mathrm{G} 3(30 \mathrm{mM}$ de mio-inositol) apresentou o menor parâmetro cinético. Sabe-se que o mio-inositol é precursor do fosfatidilinositol, molécula essencial para o metabolismo celular. O fosfatidilinositol tem ef eito estimulante na célula espermática, aumentando as taxas de glicólise, respiração celular e aumento da motilidade (Voglmayr e Amann, 1973). A alta concentração de mio-inositol associada a esta temperatura, possivelmente potencializou $\mathrm{o}$ metabolismo celular, estimulando o ciclo de Krebs, $\beta$-oxidação e fosforilação oxidativa na produção de adenosina trifosfato (ATP) por meio da respiração aeróbica na mitocôndria como observado por Câmara e Guerra (2008). No processo de respiração, 1 a $3 \%$ dos elétrons envolvidos na cadeia transportadora de elétrons determinam a formação de ERO (Guerin et al., 2001), que em concentrações reduzidas medeia funções essenciais para a fecundação do óvulo pelo espermatozoide, como a capacitação, hiperativação e reação acrossomal como sugerido por Câmara e Guerra (2008). Possivelmente, a potencialização metabólica induzida pelo mio-inositol estimulou a respiração mitocondrial induzindo a maior produção de espécies reativas de oxigênio, provocando o estresse oxidativo com consequente lesões na membrana mitocondrial, além de diminuir o aporte energético requerido pela célula espermática.
Os dados sobre a integridade e funcionalidade da membrana espermática evidenciam que a preservação dessas características no espermatozoide caprino não foi influenciada pela adição de mio-inositol. Entretanto, segundo Baumber et al. (2000), a diminuição da motilidade espermática pode ocorrer mesmo que não seja detectada a presença de diminuição em outros parâmetros de avaliação, como a integridade da membrana plasmática.

Assim, outros testes devem ser realizados para complementar este estudo, como a atividade mitocondrial, que atrelada à redução da motilidade observada neste experimento, pode indicar a ação direta do mio-inositol como potencializador da função mitocondrial, caso utilizado em altas concentrações. Esta hipótese é sustentada pela variação da concentração deste antioxidante na fisiologia reprodutiva masculina, uma vez que menores concentrações de mio-inositol são encontradas na cauda do epidídimo, segundo Hinton et al. (1980), local onde os espermatozoides diminuem seu potencial cinético para minimizar o consumo energético.

\section{Conclusão}

A adição de mio-inositol a $30 \mathrm{mM}$ interfere negativamente na motilidade de espermatozoides caprinos após $2 \mathrm{~h}$ de incubação a $37^{\circ} \mathrm{C}$, entretanto, as concentrações de 5,15 e $30 \mathrm{mM}$ deste antioxidante não exercem influência sobre a integridade $\mathrm{e}$ funcionalidade da membrana plasmática.

\section{Conflito de Interesse}

Os autores declaram não haver conflitos de interesse.

\section{Comitê de Ética}

Como foram utilizadas amostras espermáticas cedidas por uma Central de Reprodução, não houve o uso de animais vivos na experimentação, o que descaracteriza a necessidade de aprovação do projeto/trabalho em Comissão de Ética no Uso de Animais (CEUA).

\section{Referências}

Affonso, F.J.; Carvalho, H.F.; Lançoni, R.; Lemes, K.M.; Leite, T.G.; Oliveira, L.Z.; Celeghini, E.C.C.; Arruda, R.P. Addition of antioxidants myoinositol, ferulic acid, and melatonin and their effects on sperm motility, membrane integrity, and reactive oxygen species 
production in cooled equine semen. Journal of Equine Veterinary Science, 59: 57-63, 2017.

Assumpção, M.E.O.D.; Haipeck, K.; Lima, A.S.; Mello M.R.B.; Oliveira, L.J.; Oliveira, V.P.; Tavares, L.M.T.; Visintin, J.Á. Capacitação espermática in vitro com heparina e cálcio ionóforo e sua correlação com a fertilidade em touros. Brazilian Journal of Veterinary Research and Animal Science, 39(3): 14956, 2002.

Baumber, J.; Ball, B.A.; Gravance, C.G.; Medina, V.; Davies-Morel, M.C.G. The effect of reactive oxygen species on equine sperm motility, viability, acrosomal integrity, mitochondrial membrane potential, and membrane lipid peroxidation. Journal of Andrology, 21(6): 895-902, 2000.

Borges, J.C.; Silva, M.R.; Guimarães, J.D.; Esper, C.R.; Franceschini, P.H. Membrana plasmática de espermatozoides bovinos: efeito de metabólitos do oxigênio, antioxidantes e criopreservação. Revista Brasileira de Reprodução Animal, 35(3): 303-14, 2011.

Bucak, M.N.; Atessahin, A.; Yuce, A. Effect of anti-oxidants and oxidative stress parameters on ram semen after the freeze-thawing process. Small Ruminant Research, 75(2-3): 128-34, 2008.

Câmara, D.R.; Guerra, M.M.P. Mitocôndria espermática: além da síntese de adenosina trifosfato (ATP). Revista Brasileira de Reprodução Animal, 32(2): 93-9, 2008.

COLÉGIO BRASILEIRO DE REPRODUÇÃO ANIMAL (CBRA). Manual para exame andrológico e avaliação de sêmen animal. $3^{\text {a }}$ ed. Belo Horizonte: CBRA, 2013.

Condorelli, R.A.; La Vignera, S.; Bellanca, S.; Vicari, E.; Alogero, A.E. Myoinositol: does it improve sperm mitochondrial function and sperm motility? Urology, 79(6): 1290-5, 2012.

Croze, M.L.; Soulage, C.O. Potential role and therapeutic interests of myo-inositol in metabolic diseases. Biochimie, 95(10): 181127, 2013.

Flesch, F.M.; Gadella, B.M. Dynamics of the mammalian sperm plasma membrane in the process of fertilization. Biochimica et Biophysica Acta, 1469(3): 197-235, 2000.

Guerin, P.F.; Mouatassim, S.; Menezo, Y. Oxidative stress and protection against reactive oxygen species in the pre- implantation embryo and its surroundings. Human Reproduction Update, 7(2): 175-89, 2001.

Hinton, B.T.; White, R.W.; Setchell, B.P. Concentrations of myo-inositol in the luminal fluid of the mammalian testis and epididymis. Journal of Reproduction and Fertility, 58(2): 385-99, 1980.

Kulaksiz, R.; Bucak, M.N.; Akcay, E.; Ssakin, F.; Daşkin, A.; Ateşşahin, A. The effects of different extenders and myo-inositol on postthaw quality of ram semen. Kafkas Universitesi Veteriner Fakultesi Dergisi, 17(2): 217-22, 2011.

La Falci, V.S.N.; Tortorella, H.; Rodrigues, J.L.; Brandelli, A. Seasonal variation of goat seminal plasma proteins. Theriogenology, 57(3): 1035-48, 2002.

Mariante, A.S.; Albuquerque, M.S.M.; Ramos, A.F. Criopreservação de recursos genéticos animais brasileiros. Revista Brasileira de Reprodução Animal, 35(2): 64-8, 2011.

Melo, M.I.V.; Henry, M. Teste hiposmótico na avaliação de sêmen equino. Arquivo Brasileiro de Medicina Veterinária e Zootecnia, 51: 71-78, 1999.

Oliveira, I.R.S.; Alves, H.M.; Castelo, T.S.; Bezerra, F.S.B.; Bezerra, A.C.D.S.; Silva, A.R. Correlações entre o teste hiposmótico e a avaliação clássica do sêmen de caprinos. Ciência Animal Brasileira, 14(2): 216-21, 2013.

Oliveira, L.; Ribeiro, L.; Silva, L. G.; Oliveira, C.; Dias, E. A.; Campanholi, S.; Campos, C.; Oliveira, M.; Monteiro, F. Avaliação de diferentes desafios espermáticos in vitro e da fertilidade in vivo de partidas de sêmen bovino. Brazilian Journal of Veterinary Research and Animal Science, 54(3): 26476, 2017.

Patricio, A.; Cruz, D.F.; Silva, J.V.; Padrão, A.; Correia, B.R.; Korrodi-Gregório, L.; Ferreira, R.; Maia, N.; Almeida, S.; Lourenço, J.; Silva, V.; Fardilha, M. Relation between seminal quality and oxidative balance in sperm cells. Acta Urológica Portuguesa, 33(1): 6-15, 2016.

Pruneda, A.; Yeung, C.H.; Bonet, S.; Pinart, E.; Cooper, T.G. Concentrations of carnitine, glutamate and myo-inositol in epididymal fluid and spermatozoa from boars. Animal Reproduction Science, 97(3-4): 344-55, 2007. 
Sidhu, K.S.; Guraya, S.S. Cellular and molecular biology of capacitation and acrosome reaction in mammalian spermatozoa. International Review of Cytology, 118: 231-69, 1989.

Voglmayr, J.K.; Amann, R.P. The distribution of free myo-inositol in fluids, spermatozoa and tissues of the bull genital tract and observations on its uptake by the rabbit epididymis. Biology of Reproduction, 8(4): 504-13, 1973.

Yanagimachi, R. Mammalian fertilization. The physiology of reproduction. New York: Raven Press, p.189-317, 1994. 